\title{
Effect of single and mixed inoculation of arbuscular mycorrhizal fungi and phosphorus fertilizer application on corn growth in calcareous soil
}

\author{
LILY ISHAQ", A.S.J. ADU TAE, MORESI A. AIRTHUR, PETERS O. BAKO \\ Faculty of Agriculture, Universitas Nusa Cendana. Jl. Adisucipto, Penfui, Kota Kupang 85001, East Nusa Tenggara, Indonesia. Tel.: +62-380-881085, \\ vemail: lily.ishaq@yahoo.com
}

Manuscript received: 31 December 2020. Revision accepted: 24 March 2021.

\begin{abstract}
Ishaq L, Tae ASJA, Airthur MA, Bako PO. 2021. Effect of single and mixed inoculation of arbuscular mycorrhizal fungi and phosphorus fertilizer application on corn growth in calcareous soil. Biodiversitas 22: 1920-1926. Low availability of soil phosphorus (P) in calcareous soil in West Timor has become a constraint in improving plant productivity. A field experiment was carried out in the calcareous soil to investigate the effect of single and mixed indigenous arbuscular mycorrhizal fungi (AMF) inoculation and P fertilizer application on growth and yield of corn in Kupang District, East Nusa Tenggara Timur Province, Indonesia. The experiment was laid out in a split-plot design consisting of indigenous AMF inoculation as the main plots and inorganic P fertilizer rates as the sub-plot treatments. The main plot treatments were: without AMF inoculation (M0), inoculated with single AMF inoculum (M1) and inoculated with mixed AMF inocula (M2). Sub-plots consisted of four P rates namely 25\% (P1), 50\% (P2), 75\% (P3) and 100\% (P4) of the recommended inorganic superphosphate dose of $200 \mathrm{~kg} \mathrm{SP} 36$ ha-1. The results showed that there were significant interactions between AMF inoculation and $\mathrm{P}$ fertilizer dose on AMF spore density, AMF colonization and soil available P. Results indicated a strong correlation between AMF colonization and soil available P. Inoculation of both M1 and M2 significantly increased soil available P, plant growth and yield compared to the uninoculated plant. Spore production in the two AM responded differently to P fertilizer. Low doses of inorganic P fertilizer favored spore production in M1, whereas P fertilizer sporulation in M2 was adversely affected. The percentage of AMF root colonization of M1 and M2 decreased with an increase in P fertilizer applied. Further studies need to be conducted to evaluate the effectiveness of indigenous AMF in improving plant yield at low level of inorganic fertilizer application to achieve more sustainable agricultural practice in the region.
\end{abstract}

Keywords: Calcareous soil, indigenous arbuscular mycorrhiza, inorganic P fertilizer, soil available P

\section{INTRODUCTION}

East Nusa Tenggara in Indonesia is a semi-arid region with average annual rainfall ranging between 1250-1500 $\mathrm{mm}$ per year. In Timor Island, the soils are calcareous. Calcareous soils are characterized by the mineral calcium carbonate $\left(\mathrm{CaCO}_{3}\right)$ presence in the parent material and the accumulation of lime. In this soil, phosphorus (P) availability, one of the most important nutrients for plant growth, development and reproduction, is usually low and it became one of the most important factors limiting plant growth (Leytem and Mikkelsen 2005). Phosphorus fixation can occur through adsorption on a combination of clay and lime surfaces, and precipitation of various calcium phosphate minerals. When $\mathrm{P}$ fertilizer is added to calcareous soils it is converted to less soluble compounds such as dicalcium phosphate dehydrate or octacalcium phosphate, and eventually, it may convert to hydroxy phosphate, resulting in decreased solubility and availability of P to plants (Brady and Weil 2002). Despite the constraint of calcareous soils, they can be more productive for agricultural use when managed properly (Leytem and Mikkelsen 2005).

Corn is the major crop grown in the region mainly for human consumption and animal feed. Like other crops in the region field, inorganic $\mathrm{P}$ fertilizer is commonly applied to meet crop requirements for $\mathrm{P}$. However, not all the $\mathrm{P}$ applied become available for crop uptake due to natural fixation by calcium minerals, therefore, it should be applied at a high dose to ensure that sufficient $\mathrm{P}$ is available to optimize crop yield. On the other hand, excessive use of chemical fertilizers induces environmental problems and can reduce soil quality. Therefore, other approaches should be considered to improve plant uptake of $\mathrm{P}$ from soil and the efficient use of $\mathrm{P}$ fertilizer in managing calcareous soils in Timor Island. Arbuscular mycorrhizal fungi (AMF) can improve plant growth and productivity of crops in calcareous soil in Timor. Arbuscular mycorrhizal fungi are obligate symbiotic mutualisms between beneficial soil fungi and higher plants, which belong to the subphylum Glomeromycotina (Smith and Read 2008; Spatafora et al. 2016). The symbiotic association between plants and AMF is widespread among the majority of agricultural plants, and is of particular importance in improving plant $\mathrm{P}$ uptake (Smith et al. 2011). In exchange for carbohydrates from the host plants, the microsymbiont provides benefit to their host by enhancing the absorption of mineral nutrients, most notably $\mathrm{P}$, from soil. The AMF hyphae promote physiological responses in the host such as root branching and increased phosphatase secretion that indirectly promotes phosphate uptake (Smith et al. 2011). It has been reported that increased uptake of $\mathrm{P}$ by AMF results mainly from the increased soil volume exploited by the mycorrhizal root (Smih and Read 2008). In addition to their 
contribution to plant nutrition, AMF is known to improve plant resistance to abiotic stress such as drought (Quiroga et al. 2017) and salinity (Evelin et al. 2019), and they provide other ecosystem services such as improving soil structure (Leifheit et al. 2014).

Arbuscular mycorrhizal fungi may differ greatly in their responses to $\mathrm{P}$ fertilization. For instance, high phosphate conditions have been reported to significantly reduce AMF colonization (Higo et al. 2020). However, the response of AMF to fertilization may be related to genetic variation of AMF species/isolates (Wang et al. 2016). Moreover, high $\mathrm{P}$ supply may reduce root colonization while optimum $\mathrm{P}$ may increase root colonization and fungal richness (Liu et al. 2016). In general, the formation and growth of AMF are impacted by high $\mathrm{P}$ supply levels in pot experiments under controlled conditions. The effect of $\mathrm{P}$ fertilizer on AMF abundance and community structure is more variable under field conditions (Liu et al. 2016).

Accordingly, the benefits that AMF provides to host plants may greatly vary depending on the AMF strain (Smith et al. 2011). Since indigenous AMF have already adapted to the prevailing local condition, they could be more effective for promoting plant growth at that site compared to exogenous AMF. The use of appropriate AMF, either individually or in combination to promote plant nutrient uptake and performance is a major challenge. Until now, no studies have been conducted in calcareous soil in the Timor region to investigate the potential use of indigenous $\mathrm{AMF}$ to improve plant growth especially regarding fertilization with inorganic $P$. Therefore, a field experiment was conducted in the calcareous soil to investigate the effect of single and mixed indigenous arbuscular mycorrhizal fungi (AMF) inoculation and $\mathrm{P}$ fertilizer on corn growth and yield.

\section{MATERIALS AND METHODS}

\section{Research location and site preparation}

The experiment was carried out on a private farmer's land, $102 \mathrm{~m}$ above sea level, on an Inceptisol (USDA) in Penfui village Kupang, East Nusa Tenggara, Indonesia. The research plots were located on uncultivated flat land that was overgrown with woody shrubs and grass. Soil samples were taken from the land for AMF assessment and chemical analysis prior to clearing. The vegetation was manually cleaned, and the soil was cultivated with a hand tractor to a depth of $30 \mathrm{~cm}$.

\section{Experimental design}

The experiment was conducted in a Split plot design that includes arbuscular mycorrhiza fungal inoculation (M) as the main plots and inorganic $\mathrm{P}$ fertilizer $(\mathrm{P})$ as the subplot treatments. Inorganic $\mathrm{P}$ fertilizer was applied as superphosphate (SP36, 36\% $\left.\mathrm{P}_{2} \mathrm{O}_{5}\right)$ based on the recommended dose of $200 \mathrm{~kg}$ SP36 ha ${ }^{-1}$. The main plots consisted of three treatments i.e. without AMF inoculation (M0), inoculation with single AMF inoculum (M1) and inoculation with mixed AMF inocula (M2). Subplot treatments consisted of four levels of inorganic $\mathrm{P}$ fertilizer namely P1 25\% (1.25 g plant $^{-1} \mathrm{SP} 36$ equals $\left.50 \mathrm{~kg} \mathrm{ha}^{-1}\right), \mathrm{P} 2$ $50 \%$ (2.5 g plant $^{-1}$ SP36 equals $\left.100 \mathrm{~kg} \mathrm{ha}^{-1}\right)$, P3 75\% (3.75 $\mathrm{g}_{\text {plant }}^{-1} \mathrm{SP} 36$ equals $150 \mathrm{~kg} \mathrm{ha}^{-1}$ ), and P4 100\% (5 $\mathrm{g} \mathrm{plant}^{-}$ ${ }^{1}$ SP36 equals $\left.200 \mathrm{~kg} \mathrm{ha}^{-1}\right)$. All treatments were done in triplicate and there were 36 experimental units in total.

Plots $2 \times 2 \mathrm{~m}$ in size were prepared for growing the corn plants. The 36 plots were arranged in three replicates of the main plot treatment, each consisting of 12 plots ( 9 plots for each of four inorganic $\mathrm{P}$ fertilizer treatments). All the treatments were placed randomly, starting from the main-plot treatment followed by placement of sub-plot treatment within each of the assigned main-plot treatments. The spacing between sub-plots was $80 \mathrm{~cm}$, and between the main plots spacing was $1.5 \mathrm{~m}$.

\section{Inoculum}

The AMF inocula were obtained from propagation pots of indigenous arbuscular mycorrhiza previously collected from cornfields in the region (Ishaq et al. 2017), where the AMF spores were propagated in an autoclaved soil using corn as the trap plant. The single pot culture contained only Glomus sp., and the mixed pot culture contained a mixture of a Glomus sp., Scutellopsora sp., and Acaulospora sp. The Glomus sp. in the mixed pot culture was the same isolate as in the single pot culture. Spore density of the single AMF pot culture and the mixed AMF pot culture were 121 and 92 spore $100 \mathrm{~g}^{-1}$, respectively. The inoculum was applied to soil (61.98 and $81.52 \mathrm{~g}$ per plant for M1 and M2 treatments, respectively) containing 75 spores.

\section{Plant cultivation}

Corns (Lamuru variety, 90-94 days to harvest) were planted in the first week of May 2017 (dry season). The seeds were surface sterilized with $5 \%$ sodium hypochlorite for $1 \mathrm{~min}$ and rinsed three times with sterile water before use. The inoculum was manually placed in planting holes $50 \mathrm{~mm}$ deep, and $60 \mathrm{~mm}$ diameter. Sterile soil was used for the control treatment. They were watered until quite moist, and then covered with soil to around half of the planting hole depth. Corn seed ( 3 per hole) was placed in the planting hole and covered with the soil. The spacing between holes was $500 \times 500 \mathrm{~mm}$. Plants were thinned at 10 days after emergence to one plant per hole of uniform size. Inorganic $\mathrm{P}$ fertilizer was applied according to the assigned treatments.

The corn plants were provided with basal fertilizer $5 \mathrm{~g}$ urea plant ${ }^{-1}$ (200 kg ha-1, $500 \times 500 \mathrm{~mm}$ plant spacing), and $3.7 \mathrm{~g} \mathrm{KCl} \mathrm{plant}^{-1}\left(150 \mathrm{~kg} \mathrm{ha}^{-1}\right)$. These fertilizers and the rates were based on the local government recommendation. The fertilizers (all of the $\mathrm{KCl}$, half of the urea, and the $\mathrm{P}$ treatment) were manually applied to the plants around $7 \mathrm{~cm}$ from the base of the plants at $5 \mathrm{~cm}$ depth at one week after planting. The remaining area was applied at 4 weeks after planting. Plants were watered daily to around field capacity using tap water.

Plants were harvested when they were 3 months old (the second week of August 2017). The shoots were cut at the soil surface, and dried at $65^{\circ} \mathrm{C}$ to constant weight. Root and soil samples were taken from the soil around $5 \mathrm{~cm}$ from the base of the plant using a soil corer $(20 \mathrm{~cm}$ deep 
and $5 \mathrm{~cm}$ diameter) at four positions (north, south, east and west) of the stem. Roots were manually separated from the soil and washed on a $2 \mathrm{~mm}$ screen with tap water, immersed for a few mins in a beaker of water and then agitated to remove most of the organic matter and soil particles. The roots were washed again with tap water on a $2 \mathrm{~mm}$ screen. The fine roots were manually separated from the coarse roots in a Petri dish and then fixed in $50 \%$ ethanol (EtOH) for mycorrhizal assessment. The same soil samples were used for AMF spore assessment and soil available $\mathrm{P}$ analysis.

\section{Mycorrhizal assessment}

Mycorrhizal assessment was based on the protocols described by Brundrett et al. (1996). Briefly, EtOH-fixed root samples (1-2 g) were cleared in $10 \%(\mathrm{w} / \mathrm{v}) \mathrm{KOH}$ in an autoclave for $15 \mathrm{mins}$ at $121^{\circ} \mathrm{C}$, strained over $160 \mu \mathrm{m}$ nylon mesh, rinsed with water and stained with $0.05 \%$ (w/v) trypan blue (CI 23850) in lactoglycerol (1:1:1 lactic acid, glycerol and water) overnight. The roots were destained with $50 \%$ glycerol to remove excess dye.

The presence of arbuscules and/or vesicles within the root was observed under a compound microscope (Leica Galen III) and used to determine AMF colonization in 25$30 \mathrm{~cm}$ of root length for each sample with the gridline intersect method.

\section{AMF spore density}

Spores of AMF were extracted from $100 \mathrm{~g}$ soil subsamples using the wet-sieving and sucrose methods (Brundrett et al. 1996). Roots and coarse debris were collected on a coarse screen $(500 \mu \mathrm{m})$, while spores were captured on finer screens $(297,150$ and $45 \mu \mathrm{m})$. The AMF spores were isolated and counted manually under a compound microscope (Leica Galen III). The broken spores were not included in the isolation process. Spore density for each treatment was an average of 3 replicates.

\section{Soil analysis}

A composite of soil samples $(20 \mathrm{~cm}$ depth $)$ of the research site was analyzed for soil chemical properties including $\mathrm{pH}\left(\mathrm{H}_{2} \mathrm{O}\right)$, total nitrogen (Kjeldahl method), organic Carbon $(\mathrm{C}$; loss on ignition method), total and available $\mathrm{P}$ (Olsen method), and exchangeable potassium (K; Colwell method) at the Soil Laboratory of Agriculture Faculty of Nusa Cendana University, East Nusa Tenggara, Indonesia. Soil samples for each treatment at the end of the experiment were sent to Soil Laboratory of Agriculture Faculty of Brawijaya University, East Java, Indonesia for available $\mathrm{P}$ analysis (Olsen method).

\section{Observation and data analysis}

The observed variables included the number of AMF spores, AMF colonization, soil available $\mathrm{P}$, plant biomass, and cob weight. Cob weight was measured for the $4 \mathrm{~m}^{2}$ subplots. The data were subjected to analysis of variance to determine the treatment effects and Pearson's correlation coefficients were applied to determine the correlation between AMF colonization and soil available $\mathrm{P}$, and between AMF colonization and cob weight. These analyses were performed using MS Excel.

\section{RESULTS AND DISCUSSION}

\section{Soil chemical properties}

The result showed that organic- $\mathrm{C}$ and total-N in the soil were 2.85 and $0.31 \%$, respectively and classified as moderate. Available P was $9.8 \mathrm{mg} \cdot \mathrm{kg}^{-1}$ and was classified as very low, while total $\mathrm{P}$ was $85.29 \mathrm{mg} \cdot \mathrm{kg}^{-1}$ and categorized as very high. Exchangeable Potassium (K) was 0.6 meq. $100 \mathrm{~g}^{-1}$ and classified as high, and the acidity $(\mathrm{pH})$ of the soil was slightly acid (Table 1).

\section{AMF spore density}

Two-way ANOVA showed that there were significant interactions between the main factor of AMF inoculation and $\mathrm{P}$ treatment for AMF spore density. The lowest AMF spore density was without AMF inoculation despite $\mathrm{P}$ treatment. The number of spores produced differed with inoculation treatment. In the single (M1) inoculum treatment, the AMF spore density was highest at P1 and P2, and then declined at P3 and P4 (Figure 1). In contrast, in the mixed inocula (M2) treatment, spore density was not affected by the $\mathrm{P}$ treatment, and overall spore densities were intermediate compared to the single inoculum treatments (Figure 1).

Table 1. Chemical properties of soil

\begin{tabular}{lll}
\hline Soil variable & Criteria*) & \\
\hline Organic $\mathrm{C}(\%)$ & 2.85 & Moderate \\
Total N $(\%)$ & 0.31 & Moderate \\
Available $\mathrm{P}\left({\left.\mathrm{mg} . ~ \mathrm{~kg}^{-1}\right)}^{\text {Total P }\left(\mathrm{mg} . \mathrm{kg}^{-1}\right)}\right.$ & 9.8 & Very low \\
Exchangeable K $($ meq.100g & 85.29 & Very high \\
$\mathrm{pH}$ & 0.6 & High \\
Note: *): Indonesian Centre for Agricultural & Soil Resources \\
Research and Development (ICALRD) (2009). &
\end{tabular}

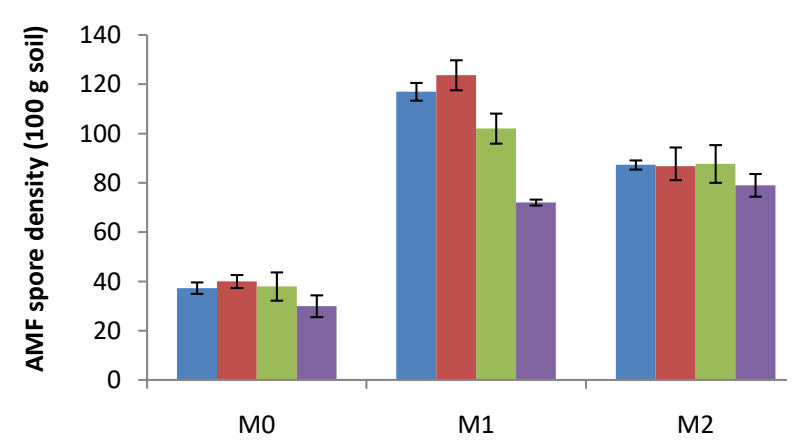

Figure. 1. Spore density of AMF per $100 \mathrm{~g}$ soil of treatment in the rhizosphere of corn without inoculation (M0), inoculated with single inoculum (M1) or mixed inocula (M2) at four level of inorganic $\mathrm{P}$ fertilizer (P1 to $\mathrm{P} 4)$. Bars represent mean values $\pm \mathrm{SE}$ $(\mathrm{n}=3)$ 


\section{AMF colonization}

Two-way ANOVA showed that there were significant interactions between AMF inoculation and $\mathrm{P}$ fertilizer on AMF colonization. Unsurprisingly, AMF colonization was much lower without AMF inoculation (M0) treatment compared to the inoculation treatment (M1, M2). Inoculation with a single inoculum or mixed inocula showed a similar trend of lower percentage of root colonized by AMF with increased $\mathrm{P}$ application (Figure 2).

\section{Soil available $\mathbf{P}$}

Two-way ANOVA showed that there were significant interactions between AMF inoculation and $\mathrm{P}$ fertilization on soil available P. Available $\mathrm{P}$ in soil increased with inorganic $\mathrm{P}$ fertilizer. Interestingly, soil available $\mathrm{P}$ in the inoculation treatment (M1, M2) was much higher compared to the treatment without AMF inoculation (M0) (Figure 3). Moreover, Spear's correlation analysis showed that AMF colonization was positively correlated $(r=0.79)$ to soil available $\mathrm{P}$ (Figure 4).

\section{Shoot dry weight}

Statistical analysis showed that there was no interaction ( $p>0.05$ ) between the regime of $P$ inorganic fertilizer and AMF inoculation on the dry weight of corn (excluding the cobs), but the main factor of AMF inoculation significantly increased plant biomass dry weight with the highest biomass in the single inoculum (M1) treatment (Figure 5).

\section{Cob weight}

There was no interaction between the regime of inorganic $\mathrm{P}$ fertilizer applied and AMF inoculation on the cob weight of corn. However, AMF inoculation with both single inoculum and mixed inocula significantly increased cob weight (Figure 6). Cob weight without AMF inoculation was only $54.13 \mathrm{~g} \mathrm{plant}^{-1}$, however, inoculation with single and mixed inocula was 142.84 and $108.94 \mathrm{~g}$ plant $^{-1}$, respectively. AMF inoculation increased the weight of corn cob with $163.9 \%$ and $101.2 \%$ with single inoculum and mixed inocula treatment, respectively. Moreover, Spear's correlation analysis showed that there was a positive correlation $(r=0.69)$ between AMF colonization and cob weight (Figure 7).

\section{Discussion}

This study showed that inoculation of AMF enhanced vegetative and reproductive growth of corn in calcareous soil. Single and mixed inocula of AMF responded differently to the dosage of inorganic $\mathrm{P}$ fertilizer applied. Low doses of P (50 and $100 \mathrm{~kg} \mathrm{SP}_{6} \mathrm{ha}^{-1}$ ) did not affect the sporulation of AMF in the single inoculum treatment, but it significantly reduced the spore density of AMF in the mixed inocula treatment. Moreover, higher $\mathrm{P}$ amount resulted in reduced AMF colonization both in the single and mixed inoculation treatments.

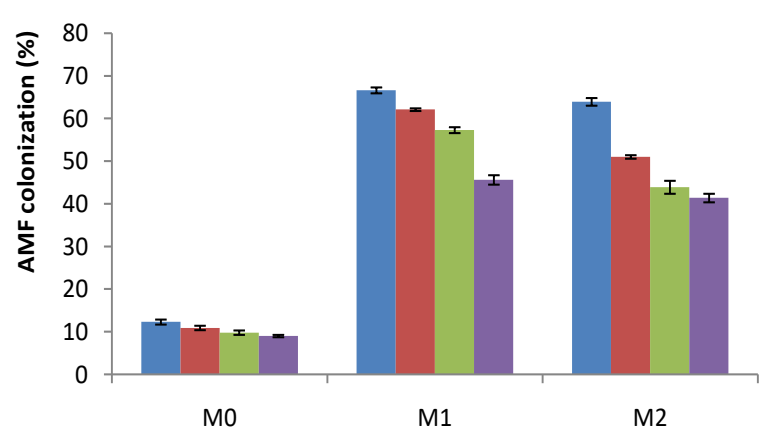

Figure 2. Percentage AMF colonization in root length of corn in treatment without inoculation (M0) and inoculated with single inoculum (M1) or mixed inocula (M2) at four levels of inorganic $\mathrm{P}$ fertilizer ( $\mathrm{P} 1$ to $\mathrm{P} 4)$. Bars represent mean values $\pm \mathrm{SE}(\mathrm{n}=3)$.

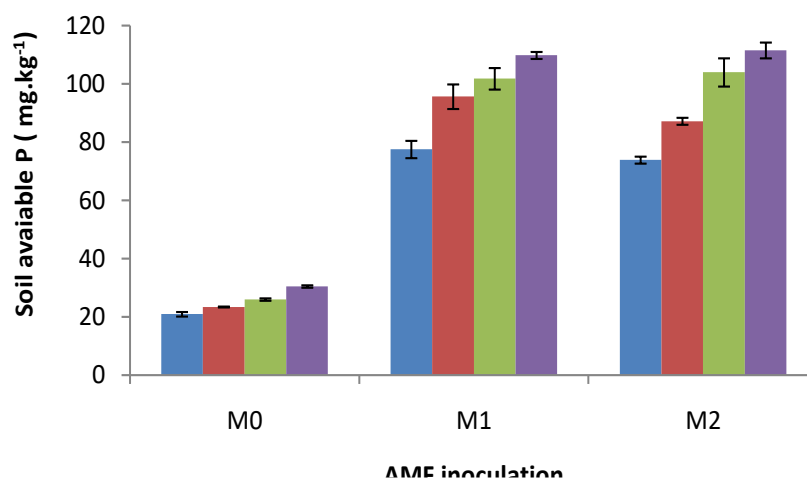

Figure 3. Soil available $\mathrm{P}$ at the time of harvest of treatment without inoculation (M0) and inoculated with single inoculum (M1) or mixed inocula (M2) at four levels of inorganic P fertilizer (P1 to $\mathrm{P} 4)$. Bars represent mean values $\pm \mathrm{SE}(\mathrm{n}=3)$

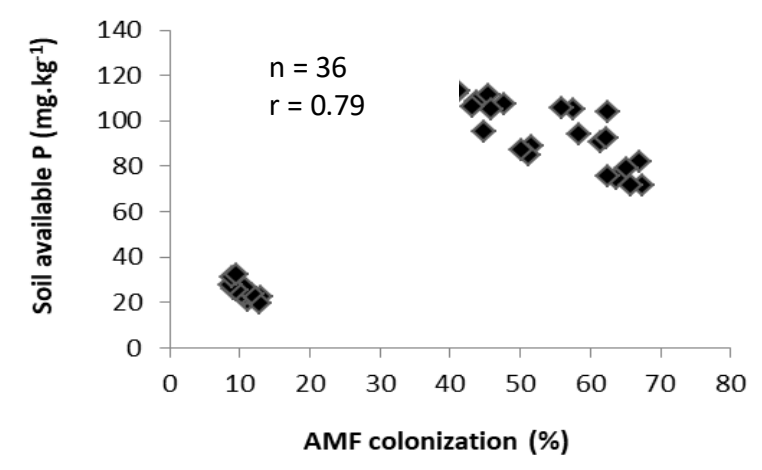

Figure 4. Correlation between AMF colonization and soil available $\mathrm{P}$ 
AMF can enhance plant $\mathrm{P}$ acquisition that is correlated with the extension of extra radical hyphae networks in soil (Smith et al. 2011; Ezawa and Saito 2018). However, AMF themselves are strongly controlled by soil $\mathrm{P}$ availability and host $\mathrm{P}$ status. Studies on the impact of inorganic $\mathrm{P}$ fertilization on AMF have yielded mixed results. For example, high phosphate conditions significantly decreased AMF colonization (Liu et al. 2012). However, it has also been reported that high $\mathrm{P}$ supply can reduce root colonization while optimum-P could increase root colonization and fungal richness (Liu et al. 2016). In this study, it was found that the type of AMF inoculum responded differently to the dosage of inorganic $\mathrm{P}$ fertilizer. The single inoculum of AMF (Glomus sp.) seemed to be less sensitive to the lower $\mathrm{P}$ fertilization rate in production of spores compared to the mixed AMF that was more sensitive to $\mathrm{P}$ fertilization. Different responses between single and mixed AMF inocula to the dose of inorganic $\mathrm{P}$ applied in producing spore might be due to genetic variability of AMF species/isolate, particularly their sensitivity to inorganic fertilizer. It is well known that $\mathrm{P}$ fertilization reduces soluble carbon in the root apoplast (Smith and Read 2008), and possibly decreases the amount of soluble carbohydrate content in root exudates. Since AMF might differ in terms of the requirement of soluble carbohydrate (Smith and Read 2008) and competitive potential for host carbohydrate (Bennet and Bever 2009), their responses to inorganic fertilizer application could be variable. The results of this study showed that AMF inocula responded differently to $\mathrm{P}$ fertilization. However, it is unknown whether Glomus sp. was the only species that persisted at the high $\mathrm{P}$ rates. Therefore, to have understood about this, in addition to spore density, the population of AMF spores should also be determined at the start as well as at the end of the trials to evaluate the persistence and competitive ability of the different AMF species.

While the effect of inorganic $\mathrm{P}$ fertilizer on spore density differed between single and mixed AMF inocula, the effect of the increased dose of inorganic $\mathrm{P}$ fertilizer was more pronounced on root colonization. The percentage of roots colonized by AMF both in single and mixed inocula treatments declined markedly with an increase in inorganic $\mathrm{P}$ supply. Previously, it has been demonstrated that high $\mathrm{P}$ supply could impact on root colonization (Balzergue et al. 2011). It has also been suggested that the production of strigolactone, root-exudate compounds that trigger morphological and developmental responses in AMF including hyphal branching and spore germination, is controlled by $\mathrm{P}$ supply although other factors might be also involved (Balzergue et al. 2011). A different result about the effect of $\mathrm{P}$ fertilization has been reported by Almagrabi and Abdelmoneim (2012). Three species of Glomus reduced the effect of $\mathrm{P}$ fertilization on maize plants, the authors found that the Glomus spp. responded differently to $\mathrm{P}$ fertilization, and, surprisingly, root colonization and spore density were high both in the without and with $\mathrm{P}$ fertilization treatments. Other studies have shown that sensitivity of AMF to fertilization could be related to genetic variation of AMF species/isolates (Bhadalung et al. 2005.; Wang et al. 2016), in which some species may be categorized as insensitive, slightly sensitive, or highly sensitive to the long term use of nitrogen and $\mathrm{P}$ fertilizers (Badhalung et al. 2005).

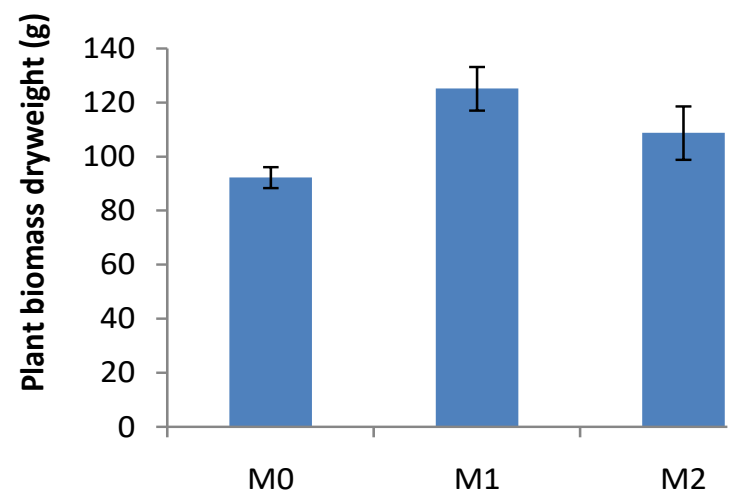

Figure 5. Corn shoot biomass dry weight (excluding the cobs) of treatment without inoculation (M0) and inoculated with single inoculum (M1) and mixed inocula (M2). Bars represent mean values $\pm \operatorname{SE}(n=12)$

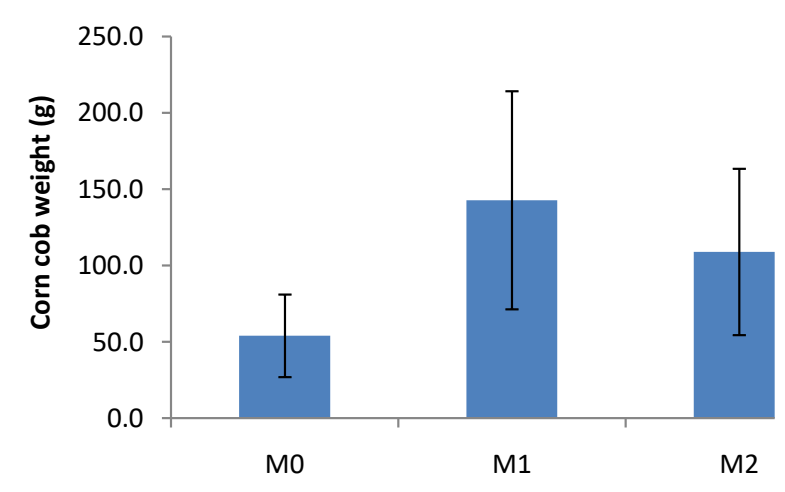

Figure 6. Corn cob weight of treatment without inoculation (M0) and inoculated with single inoculum (M1) and mixed inocula (M2). Bars represent mean values $\pm \operatorname{SE}(n=12)$

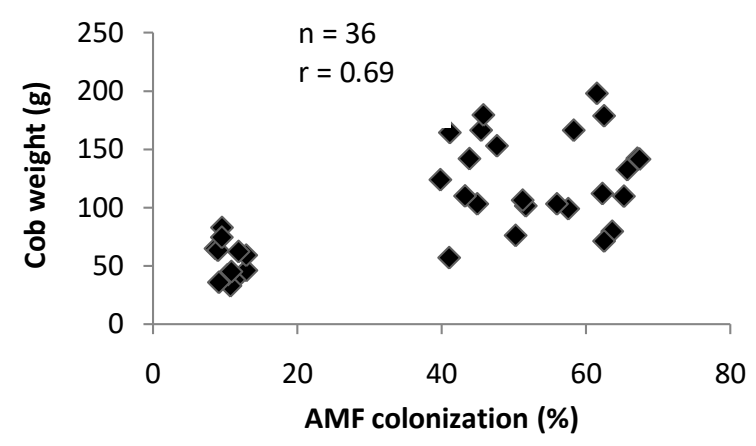

Figure 7. Correlation between AMF colonization and cob weight of corn 
In this study, as expected, soil available $\mathrm{P}$ increased with the increasing dose of inorganic $P$ supply. The increase in available $P$ was quite large, which raises the question of where the pool of available $\mathrm{P}$ is located in the soil. Interestingly, the increase in soil available $\mathrm{P}$ was more evident in the AMF inoculation treatments than in the uninoculated treatment. Similar result has been reported by Pamuna et al. (2013). Using SP-36 as a P fertilizer source combined with AMF inoculation, the authors found that higher $\mathrm{P}$ fertilizer resulted in higher $\mathrm{P}$-total in soil and $\mathrm{P}$ uptake by corn, with the higher increase occurring in the AMF treatment. Furthermore, since the number of AMF spores was linearly correlated to the available $\mathrm{P}$ in soil, the number of AMF spores in the soil has been proposed to be employed as a biological method to predict the available $\mathrm{P}$ in the soil for P fertilizer use recommendation (Effendy and Wijayani 2011). The increase in soil $P$ availability in the AMF inoculation treatments might be due to the ability of AMF to mobilize $P$ from the soil. Firstly, AMF may increase the availability of $\mathrm{P}$ in soil through their capacity to solubilize organic $\mathrm{P}$ by producing extracellular acid phosphatases (Wang et al. 2016). Secondly, AMF may recruit phosphate $(\mathrm{Pi})$ solubilizing bacteria that secret organic acid chelators for mobilizing $\mathrm{Pi}$ from sparingly soluble salts and/or phosphatize to mineralize organic $\mathrm{P}$ (Zang et al. 2016; Battini et al. 2017). Other responses influencing the $\mathrm{P}$ acquisition of mycorrhizal plants include (1) extending root volume thus decreasing the diffusion distance of Pi to plant roots and increasing the surface area for Pi absorption, (2) facilitating the uptake of Pi through an increase in affinity for Pi and a decrease in the threshold concentration for $\mathrm{Pi}$ absorption, and (iii) promoting $\mathrm{P}$ solubilization by stimulating the excretion of metabolites that increase the labile Pi pools from insoluble organic acid (Smith and Read 2008; Bindraban et al. 2020).

The contribution of AMF in improving plant health and fitness are widespread (Smith and Read 2008), where it has been related mainly to the ability of AMF to scavenge nutrition from the soil to their host plant, most notably P. In this study, it was found that there was no significant difference between $\mathrm{P}$ rates in promoting plant growth and yield, but AMF inoculation significantly improved plant growth and yield. Furthermore, inoculation with a single species tended to perform better in promoting plant growth and yield compared to using a mixture of species. This is possibly due to less competition between the isolates in the single inoculum than the mixed inocula treatment. As this study was conducted under field conditions, other indigenous AMF may have influenced the response of corn to the inoculation treatments but it remains to be investigated. Since plant growth responses to AMF inoculation are highly variable even among the isolates of the same AMF species (Smith et al. 2011), there is no substitute for field trials. It has been suggested that a major factor that differentiates plant growth responses to $\mathrm{AMF}$ could be due to the high intraspecific variability in the AMF gene repertoires (Ezawa and Saito 2018).

The single inoculum (Glomus sp.) tended to perform better than mixed inocula in improving corn growth and yield, and this isolate might become a suitable inoculum for the farmers in the region. However, this initial study was undertaken in a field that had not been cultivated, so more studies should be done in agricultural land where different crops are grown and $\mathrm{P}$ fertilizer is applied regularly to evaluate the residual effect of $\mathrm{P}$ and survival of AMF in the field over crop rotations. In conclusion, calcareous soil can be more productive if managed properly. Applying AMF inoculum could improve maize performance at low dose of inorganic $\mathrm{P}$ fertilizer, thus making it an alternative to sustainably improve the productivity of calcareous soils. More studies need to be undertaken to evaluate the ability of AMF to promote plant growth and reduce the use of inorganic $\mathrm{P}$ fertilizer.

\section{ACKNOWLEDGEMENTS}

The study was financed by a grant from Directorate General of Higher Education, Ministry of Research, Technology and Higher Education of the Republic of Indonesia under the scheme of Penelitian Unggulan Perguruan Tinggi. The author appreciated Nusa Cendana University, Kupang, Indonesia, for facilitating the research.

\section{REFERENCES}

Almagrabi OA, Abdelmonein TS. 2012. Using of arbuscular mycorrhizal fungi to reduce the deficiency effect of phosphorus fertilization on Maize plants (Zea mays L). Life Sci 9 (4): 1648-1654.

Balzergue C, Puech-Pagès V, Bécard G, Rochange SF. 2011. The regulation of arbuscular mycorrhizal symbiosis by phosphate in pea involves early and systemic signalling events. J Exp Bot 62 (3): 10491060. DOI: $10.1093 /$ jxb/erq335.

Battini F, Gronlund M, Agnolucci M, Giovannetti M, Jakobsen I. 2017. Facilitation of phosphorus uptake in maize plants by mycorrhizosphere bacteria. Sci Rep 7: 4686. DOI: 10.1038/s41598017-04959-0.

Bhadalung NaN, Suwanarit A, Dell B, Nopamornbodi BO, Thamchaipenet A, Rungchuang R. 2005. Effects of long-term NPfertilization on abundance and diversity of arbuscular mycorrhizal fungi under a maize cropping system. Plant Soil 270: 371-382. DOI: 10.1007/s11104-004-1829-4.

Bennett AE, Bever AD. 2009. Trade-offs between arbuscular mycorrhizal fungal competitive ability and host growth promotion in Plantago lanceolata. Oecologia 160: 807-816. DOI: 10.1007/s00442-0091345-6

Bindraban PS, Dimkpa CO, Pandey R. 2020. Exploring phosphorus fertilizers and fertilization strategies for improved human and environmental health. Biol Fert Soils 56: 299-317. DOI: $10.1007 / \mathrm{s} 00374=019-01430-2$.

Brady N, Weil R. 2002. The Nature and Properties of Soils. $13^{\text {th }}$ edition. Pearson Education, Inc. Upper Saddle River, New Jersey.

Brundrett M, Bougher N, Dell B, Grove T, Malajczuk N. 1996. Working with Mycorrhiza in Forestry and Agriculture. Australian Centre for International Agricultural Research, Canberra, Australia.

Effendy M, Wijayani BW. 2011. Estimation of available phosphorus in soil using the population of arbuscular mycorrhizal fungi. J Trop Soil 16 (3): 225-232. DOI: 10.5400/jts.2011.v16i3.225-232.

Evelin H, Devi TS, Gupta S, Kapoor R. 2019. Mitigation of salinity stress in plants by arbuscular mycorrhizal symbiosis: current understanding and new challenges. Front Plant Sci 10: 470 DOI: 10.3389/fpls.2019.00470.

Ezawa T, Saito K. 2018. How do arbuscular mycorrhizal fungi handle phosphate? New insight into fine-tuning of phosphate metabolism. Review. New Phytol 220: 1116-1121. DOI: 10.1111/nph.15187.

Higo M, Azuma M, Kamiyoshihara Y, Kanda A, Tatewaki, Y, Isobe K. 2020. Impact of phosphorus fertilization on tomato growth and 
arbuscular mycorrhizal fungi communities. Microorganisms 8 (2): 178. DOI: $10.339 /$ microorganisms 8020178 .

Indonesian Soil Research Institute. 2009. Chemical Analysis of Soil, Plant, Water and Fertilizer. Indonesian Agency for Agricultural Research and Development, Jakarta. [Indonesian]

Ishaq L, Adu Tae ASJ, Airthur MA, Bako PO. 2017. Shor Communication: Abundance of arbuscular mycorrhizal associated with traditional and more modern farming system in Kupang, East Nusa Tenggara Timur, Indonesia. Biodiversitas 18 (1): 887-892. DOI: $10.13057 /$ biodiv/d18034.

Leifheit EF, Veresoglou SD, Lehmann A, Morris EK, Rillig MC. 2014. Multiple factors influence the role of arbuscular mycorrhizal fungi in soil aggregation-a meta-analysis. Plant Soil 374: 523-537. DOI: 10.1007/s11104-013-1899-2

Leytem AB, Mikkelsen RL. 2005. The nature of phosphorus in calcareous soils. Better Crops 89 (2): 11-13.

Liu L, Shi G, Mao L Cheng G, Jiang S, Ma X, An L, Du G, Johnson NC, Feng H. 2012. Direct and indirect influence of $8 \mathrm{yr}$ of nitrogen and phosphorus fertilization on Glomeromycota in an alpine meadow ecosystem. New Phytol 194 (2): 523-535. DOI: 10.1111/j14698137.2012.04050.x.

Liu W, Zhang Y, Jiang S, Deng Y, Christie P, Murray PJ, Li X, Zhang J. 2016. Arbuscular mycorrhizal fungi in soil and root respond differently to phosphorus input in an intensively managed calcareous agricultural soil. Sci Rep 6: 24902 DOI: 10.103/srep 24902.

Pamuna K, Darman S, Pata'dungan YS. 2013. Effect of SP-36 fertilizer and arbuscular mycorrhizal fungi on phosphorus uptake by maize
(Zea mays L.) growth in oxic dystrudepts soil from Tongoa valley Central Sulawesi. J. Agrotekbis 1 (1): 23-29. [Indonesian]

Quiroga Q, Erice G, Aroca R, Chaumont F, Ruiz-Lozano JM. 2017. Enhanced drought stress tolerance by the arbuscular mycorrhizal symbiosis in a drought-sensitive maize cultivar is related to a broader and differential regulation of host plant aquaporins than in a droughttolerant cultivar. Front Plant Sci 8: 1506. DOI: 10.3389/fpls.2017.01056.

Smith SE, Read DJ. 2008. Mycorrhizal Symbiosis. Elsevier, New York, USA.

Smith SE, Jakobsen I, Gronlund M, Smith FA. 2011. Roles of arbuscular mycorrhizas in plant phosphorus nutrition: interactions between pathways of phosphorus uptake in arbuscular mycorrhizal roots have important implications for understanding and manipulating plant phosphorus acquisition. Plant Physiol 156: 1050-1057. DOI: 10.1104/pp.111.174581

Spatafora JW, Chang Y, Benny GL, Lazarus K, Smith ME, Berbee ML, Bonito G, Corradi N, Grigoriev I, Gryganskyi A, James TY. 2016. A phylum-level phylogenetic classification of zygomycete fungi based on genome-sclae data. Mycologia 108 (5): 1028-1046. DOI: $10.3852 / / 16-042$

Wang G, Li X, Christie P, Zang J, Li X. 2016. Response of arbuscular mycorrhizal fungi to soil phosphorus patches depends on context. Crop Pasture Sci 67: 1116-1125. DOI: 10.1071/CP16168

Zang L, Xu M, Liu Y, Zhang F, Hodge A, Feng G. 2016. Carbon and phosphorus exchange may enable corporation between an arbuscular mycorrhizal fungus and a phosphate-solubilising bacterium. New Phytol 210: 1022-1032. DOI: 10.1111/nph.13838. 